\title{
CONSUMER BEHAVIOR: CONFIDENCE \\ RELATIONSHIPS AND CONFORMITY WITH \\ CONSUMTIVE BEHAVIOR ONLINE SHOPPING \\ FASHION PRODUCTS USERS INSTAGRAM APPLICATIONS
}

\section{Nungky Irma Triyanti' Usman Effendi ${ }^{2}$}

Universitas Persada Indonesia YAl Jakarta

I N F O A R T K E L
Keyword:
Confidence, conformity, consumptive
Behavior

Corresponding author:

Usman.effend09@gmail.com
A B S T R A C T

The focus of this research on consumptive behavior is human action in an effort to fulfill the necessity of life, where most of the students to fulfill the necessities of life still depend on the assistance of parents. Therefore, in measuring consumer behavior used confidence and conformity as a parameter. The population of this research is a student of one private university in Jakarta who is considered to represent as a student community. The method used is descriptive method. Data collection methods used questionnaires with Likert scale models on the three variables of confidence, conformity and consumptive behavior. Based on multiple regression analysis obtained value of $R 2$ equal to 0,379 with $p<0,05$. So it can be concluded that there is a significant relationship between self-confidence and conformity with consumptive behavior of online shopping fashion products on the students application Instagram means that confidence and conformity contributes $37.9 \%$ towards consumptive behavior. Among self-confidence accounted for $28.2 \%$ while conformity accounted for $9.7 \%$ of consumer behavior consumptive shopping online fashion products on application students Instagram applications.

I N T I SAR I

Fokus penelitian ini pada perilaku konsumtif adalah tindakan manusia dalam upaya memenuhi kebutuhan hidup, di mana sebagian besar siswa untuk memenuhi kebutuhan hidup masih bergantung pada bantuan orang tua. Oleh karena itu, dalam mengukur perilaku konsumen digunakan kepercayaan dan kesesuaian sebagai parameter. Populasi penelitian ini adalah mahasiswa dari satu universitas swasta di Jakarta yang dianggap mewakili sebagai komunitas mahasiswa. Metode yang digunakan adalah metode deskriptif. Metode pengumpulan data menggunakan kuesioner dengan model skala Likert pada tiga variabel kepercayaan, konformitas dan perilaku konsumtif. Berdasarkan analisis regresi berganda diperoleh nilai R2 sebesar 0,379 dengan $p<0,05$. Jadi dapat disimpulkan bahwa ada hubungan yang signifikan antara kepercayaan diri dan konformitas dengan perilaku konsumtif dari produk belanja online fashion pada aplikasi siswa Instagram berarti bahwa kepercayaan dan konformitas menyumbang $37,9 \%$ terhadap perilaku konsumtif. $\mathrm{Di}$ antara kepercayaan diri menyumbang $28,2 \%$ sementara konformitas menyumbang $9,7 \%$ dari perilaku konsumen belanja online konsumtif produk fashion pada aplikasi aplikasi Instagram siswa. 


\section{PENDAHULUAN}

\section{Latar Belakang Masalah}

Perkembangan dunia teknologi di era globalisasi ini mengalami perkembangan dan kemajuan yang pesat. Globalisasi merupakan era yang menjanjikan keterbukaan dan kebebasan berekspresi, termasuk penggunaan handphone saat ini telah terhubung dengan jaringan internet yang mampu menambah pendapatan seseorang secara ekonomi dan juga dapat dijadikan sebagai sarana dalam melakukan transaksi jual beli. Setiap tahun bahkan setiap bulan selalu saja bermunculan toko-toko online dan perusahaan e-commerce. Sektor e-commerce pun telah menjadi primadona dikalangan startup. Pelakunya bukan saja dari lokal, namun ada invasi pelaku ecommerce besar luar negeri yang masuk ke Indonesia. Alasan utama mereka ialah memperluas jaringan serta menangkap pasar Indonesia. Luthfiana (20l4) menjelaskan bahwa di Indonesia masih terdapat banyak toko online, dimana transaksi pembayaran masih dilakukan dengan cara non-online, seperti transfer antar bank. Proses yang begitu mudah menjadinya individu tidak perlu lagi berpergian untuk mencari produk fashion yang sedang trend pada masanya. Kenyataan ini pada akhirnya membuat individu mempunyai pola hidup konsumtif sehingga mereka akan merasa lebih percaya diri karna telah mengikuti jaman dalam hal berpakaian dan tentunya apabila hal ini terus berlanjut akan membawa dampak yang tidak baik terhadap individu. Tambunan (dikutip dalam Ahmad Hidayat dan Candra Kurniawan, 2016) menyatakan bila individu terjerat dalam hidup yang konsumtif maka kebutuhan yang menjadi prioritas utama tidak terpenuhi, akibatnya terjadi pemborosan karena individu membelanjakan sebagian besar uangnya untuk mengejar gengsi semata dan berperilaku konsumtif untuk meningkatkan rasa kepercayaann diri mereka.

Seperti yang terlihat banyaknya masyarakat yang menggunakan fashion dengan model yang sama atau individu yang tertarik dan kemudian membeli barang tersebut, padahal ia masih mempunyai barang-barang yang layak untuk digunakan. Meida D.Wardhani (2009) menyatakan bahwa dari kelompok sebayanya, individu memperoleh informasi mengenai barang-barang yang sedang trendi sehingga mereka tidak segan-segan mengeluarkan uang demi menunjang penampilannya serta tidak dianggap ketinggalan sehingga seringkali terjadi pada individu dalam membeli barang tidak didasarkan pada faktor kebutuhan tetapi mengutamakan pemuasan kebutuhan secara psikologis saja dan menjadikan individu merasa puas apabila dapat membeli barang-barang yang oleh teman sebayanya dianggap sedang trendi sehingga hal ini dapat menyebabkan individu menjadi konsumtif karena dalam membeli barang hanya sekedar untuk mengikuti arus mode. Dengan demikian, individu akan lebih percaya diri ketika mereka telah mengikuti jaman serta mengikuti kelompok sebayanya agar tidak ingin ketinggalan dalam hal mengkonsumsi produk-produk fashion yang sedang trend tersebut.

Berdasarkan pengakuan mahasiswa ratarata mereka memiliki akun Instagram dan memanfaatkannya untuk keperluan berbelanja. Hasil wawancara dan observasi bahwa mereka lebih menyukai berbelanja secara online melalui aplikasi Instagram dibandingkan dengan tokotoko offline yang berada dipusat pembelanjaan. $\mathrm{Hal}$ ini disebabkan karena harganya relatif lebih murah dan juga lebih praktis sehingga mereka tidak perlu lagi berpergian untuk berbelanja mencari barang-barang yang diinginkan.

\section{Tujuan Penelitian}

I. Untuk mengetahui adanya hubungan kepercayaan diri dengan perilaku konsumtif berbelanja online produk fashion pada mahasiswa pengguna aplikasi Instagram.

2. Untuk mengetahui adanya hubungan konformitas dengan perilaku konsumtif berbelanja online produk fashion pada mahasiswa pengguna aplikasi Instagram.

3. Untuk mengetahui adanya hubungan kepercayaan diri dan konformitas dengan perilaku konsumtif berbelanja online produk fashion pada mahasiswa pengguna aplikasi Instagram

\section{TINJAUAN PUSTAKA}

\section{Kepercayaan Diri}

Kepercayaan diri tumbuh dari proses interaksi di lingkungan sosial, sehingga rasa percaya diri mampu membentuk psikologis seseorang untuk yakin atas tindakan yang dilakukan oleh dirinya sendiri. Hal ini serupa dengan apa yang dikatakan Thantaway (dikutip oleh Masayu, 2016) bahwa percaya diri adalah kondisi mental atau psikologis diri seseorang yang memberi keyakinan kuat pada dirinya sendiri untuk berbuat atau melakukan suatu tindakan. 
Pendapat lain mengungkapkan bahwa kepercayaan diri adalah suatu keyakinan dalam diri seseorang bahwa individu mampu meraih kesuksesan dengan berpijak pada usahanya sendiri (Lie dikutip oleh Masayu, 2016). Terbentuknya kemampuan percaya diri adalah suatu proses belajar bagaimana merespon berbagai rangsangan dari luar dirinya melalui interaksi dengan lingkungannya (Surya dikutip oleh Arie, 2016). Kepercayaan diri dapat terbentuk dalam diri individu ketika mereka memiliki keyakinan pada dirinya sendiri. Menurut Ghufron (dikutip oleh Masayu, 2016) ada beberapa faktor yang mempengaruhi kepercayaan diri yang ada pada diri individu, diantaranya adalah: faktor internal (konsep diri, harga diri, kondisi fisik dan pengalaman hidup) dan faktor eksternal (pendidikan, pekerjaan dan lingkungan). Menurut Taylor (dikutip oleh Sri Wahyuni, 2014) menyatakan bahwa rasa percaya diri (self confidence) adalah keyakinan seseorang akan kemampuan yang dimiliki untuk menampilkan perilaku tertentu atau untuk mencapai target tertentu. Sependapat dengan Hakim (dikutip oleh Selviana, 20I4) kepercayaan diri merupakan keyakinan seseorang terhadap segala kelebihan aspek yang dimilikinya dan keyakinan tersebut membuatnya merasa mampu untuk bisa mencapai berbagai tujuan di dalam hidupnya.

\section{Konformitas}

Konformitas merupakan pembentukan kelompok yang dapat merubah persepsi, opini dan perilaku individu, sehingga harus menyesuaikan diri terhadap aturan kelompok karena adanya tuntutan atau tekanan dari kelompok tersebut. Hal ini dilakukan individu agar dapat diterima dan menjadi bagian dari kelompok tersebut. Selaras dengan yang dikatakan Baron dan Byrne (dikutip oleh Masayu, 2015) bahwa konformitas sebagai suatu bentuk penyesuaian terhadap kelompok sosial karena adanya tuntutan dari kelompok sosial untuk menyesuaikan, sehingga individu lebih banyak meniru serta menyesuaikan dirinya dengan kelompok tersebut agar dapat diterima didalam kelompok itu sendiri. Begitu pula dengan Zebua dan Nurdjayadi (dikutip oleh Nur Fitriani, 2013) yang mengatakan bahwa konformitas adalah suatu tuntutan yang tidak tertulis dari kelompok teman sebaya terhadap anggotanya tetapi memiliki pengaruh yang kuat dan dapat menyebabkan munculnya perilakuperilaku tertentu pada anggota kelompok. Penelitian konformitas merupakan pengaruh sosial yang menyababkan individu dapat mengubah sikap agar mampu menyesuaikan diri didalam sebuah kelompok. Menurut Baron dan Branscombe (2012) konformitas dipengaruhi dalam beberapa faktor yang diantaranya adalah kohesivitas, ukuran kelompok, norma deskriptif dan norma injungtif.

\section{Perilaku Konsumtif}

Konsumtif merupakan perilaku yang didalamnya timbul keinginan untuk membeli barang-barang yang kurang diperlukan dan hanya untuk memenuhi kepuasan pribadi. Menurut Dwi Astuti (2013) perilaku konsumtif dapat diartikan sebagai suatu tindakan memakai produk yang tidak tuntas, artinya belum habis masa pakai sebuah produk kemudian menggunakan produk jenis yang sama dari merek yang berbeda atau dapat disebutkan membeli barang karena adanya hadiah yang ditawarkan atau membeli suatu produk karena banyak orang memakai barang tersebut. Perilaku konsumtif ini cenderung membuat individu menjadi terbiasa membeli atau mengkonsumsi barang yang sebenarnya kurang diperlukan secara berlebihan serta tidak didasari atas pertimbangan rasional. Menurut Fromm (dikutip oleh Astuti, 2013) yang menggambarkan perilaku konsumtif sebagai suatu tindakan yang tidak rasional dan bersifat kompulsif karena tujuannya terletak pada membeli itu sendiri tanpa hubungan sedikitpun dengan manfaatnya atau dengan kesenangan dalam membeli dan mengkonsumsi barang-barang. Faktor lain yang dapat memengaruhi seseorang untuk berperilaku konsumtif, diantaranya yaitu membeli barang dan jasa bukan sekedar nilai manfaatnya atau karena terdesak kebutuhan, melainkan dipengaruhi sebuah gaya hidup konsumtif yang didorong gengsi agar tidak disebut ketinggalan jaman atau sebagai tanda dari status sosial seseorang (Kristiana,20/3). Selain itu seseorang akan lebih percaya diri bila dari ujung kepala sampai ujung kaki menggunakan barang yang serba mahal dan up to date, sehingga tidak dianggap kuno (Setiana,20I3). 


\section{Kerangka Berfikir}

Adanya aplikasi Instagram individu akan dengan mudah melakukan pembelanjaan tanpa harus berpergian. Hal ini menyebabkan individu menjadi terus-menerus melihat produk-produk fashion terbaru yang yang ditawarkan pada aplikasi tersebut, sehingga individu akan memiliki keinginan untuk membeli. Membeli yang dimaksud disini tidak sesuai dengan kebutuhannya, melainkan hanya sekedar mengikuti mode agar tidak ketinggalan jaman. Tindakan ini menimbulkan adanya perilaku konsumtif dalam hal membeli barang yang kurang dibutuhkan melainkan mereka membeli hanya untuk menutupi gengsi dan mengikuti jaman. Individu yang berperilaku konsumtif ini disebabkan adanya persaingan dari faktor lingkungan yang menjadikan individu ingin terlihat fashionable dijaman yang modern ini.

Artledia (dikutip oleh Indah Haryani dan Jhon Herwanto, 2015) mengatakan bahwa salah satu faktor psikologis yang berperan dalam pembentukan perilaku membeli adalah tingkat konformitas. Semakin konform individu terhadap kelompoknya, maka semakin mudah terpengaruh berperilaku konsumtif. Menurut Meida D. Wardhani (2009) bahwa kecenderungan individu untuk menjadi konsumtif tersebut bisa merupakan indikasi bahwa mereka kurang percaya diri dan rendah diri. Seseorang menjadi konsumtif disebabkan adanya inferiority complex, yaitu perasaan kecil dan rendah diri. Untuk menutupi hal tersebut dilakukan dengan mengkonsumsi barang-barang yang trendi dan sedang menjadi mode di pergaulan. Hawkins (dikutip oleh Meida D. Wardhani, 2009) menyatakan bahwa konsumen yang tidak yakin pada dirinya sendiri dan mempunyai kepercayaan diri yang rendah akan membeli setiap produk yang mempunyai arti simbolik yang dianggap bisa menaikkan kepercayaan dirinya.

Hasil penelitian yang dilakukan oleh beberapa peneliti sebelumnya, mengungkapkan bahwa kepercayaan diri memiliki hubungan terhadap perilaku konsumtif dan sama hal nya dengan konformitas juga memiliki hubungan terhadap perilaku konsumtif berbelanja online produk fashion pada mahasiswa pengguna aplikasi Instagram.

\section{Hipotesis}

$\mathrm{HI}$ : Terdapat hubungan kepercayaan diri dengan perilaku konsumtif berbelanja online produk fashion pada mahasiswa pengguna aplikasi Instagram

H2 : Terdapat hubungan konformitas dengan perilaku konsumtif berbelanja online produk fashion pada mahasiswa pengguna aplikasi Instagram

H3 : Terdapat hubungan kepercayaan diri dan konformitas dengan perilaku konsumtif berbelanja online produk fashion pada mahasiswa pengguna aplikasi Instagram.

\section{METODE PENELITIAN}

Bentuk penelitian ini adalah kuantitatif dengan memberikan penjelasan dari karakteristik variabel yang bersifat deskriptif. Sedangkan untuk memperoleh data pokok peneltian digunakan kuesioner yang disusun berdasarkan model skala Likert yang disesuaikan dengan semua variabel yaitu kepercayaan diri, konformitas dan perilaku konsumtif dalam penelitian ini.

Dalam rangka pengujian hipotesis dan analisis data digunakan teknik perhitungan dengan analisis Bivariate Colleration dan Multivariate Colleration. Pengerjaan ini dibantu dengan menggunakan software program SPSS versi 16.0 for Windows.

\section{HASIL PENELITIAN}

Teknik perhitungan korelasi menggunakan rumus bivariate correlation dan multivariate correlation. Hipotesis pertama $(\mathrm{HI})$ : Terdapat hubungan kepercayaan diri dengan perilaku konsumtif. Hasil analisis diperoleh nilai $r$ sebesar (-)0,467 dengan $p<0,05$. Hal ini dapat disimpulkan bahwa tidak terdapat hubungan antara kepercayaan diri dengan perilaku konsumtif, artinya semakin tinggi kepercayaan diri maka pengguna aplikasi Instagram akan semakin menghindar/menjauhui dari perilaku konsumtif berbelanja online produk fashion.

Hipotesis kedua $(\mathrm{H} 2)$ : Terdapat hubungan konformitas dengan perilaku konsumtif. Hasil analisis data penelitian diperoleh nilai $r$ sebesar 0,53 I dengan $p<0,05$. Maka dapat disimpulkan bahwa terdapat hubungan yang signifikan dengan arah positif antara hubungan konformitas dengan perilaku konsumtif, artinya semakin 
tinggi konformitas maka perilaku konsumtif berbelanja online produk fashion pada mahasiswa pengguna aplikasi Instagram akan semakin tinggi.

Hipotesis ketiga $(\mathrm{H} 3)$ : Terdapat hubungan kepercayaan diri dan konformitas dengan perilaku konsumtif. Berdasarkan analisis regresi berganda pada output model summary, hasil hipotesis ketiga diperoleh $R^{2}$ sebesar 0,379 dengan $p<0,05$. Sehingga dapat disimpulkan bahwa terdapat hubungan yang signifikan antara kepercayaan diri dan konformitas dengan perilaku konsumtif, artinya semakin tinggi kepercayaan diri dan konformitas maka akan diikuti oleh perilaku konsumtif yang semakin tinggi. Koefisien determinasi atau $\mathrm{R}^{2}$ sebesar 0,379 yang berarti bahwa kepercayaan diri dan konformitas memberikan sumbangan sebesar $37,9 \%$ terhadap perilaku konsumtif, dimana kepercayaan diri memberikan sumbangan sebesar $28,2 \%$ dengan $\mathrm{R}^{2}=0,282$ dan sisanya $9,7 \%$ adalah hasil sumbangan konformitas dengan $R^{2}=0,097$ dan selebihnya sebesar $62,1 \%$ dipengaruhi oleh variabel lainnya yang tidak termasuk dalam penelitian ini.

\section{PEMBAHASAN}

Peneliti ingin menguji keterkaitan kepercayaan diri dan konformitas terhadap perilaku konsumtif berbelanja online produk fashion dengan menggunakan tiga skala yang terdiri dari skala kepercayaan diri, skala konformitas dan skala perilaku konsumtif. Pada hipotesis pertama dari hasil analisis bivariate terdapat hubungan negatif antara kepercayaan diri dengan perilaku konsumtif berbelanja online produk fashion.

Hal ini berarti apabila semakin tinggi kepercayaan diri seseorang maka akan semakin menghindar/ menjauh dari perilaku konsumtif berbelanja online produk fashion pengguna aplikasi Instagram. Penelitian ini membuktikan bahwa mendukung pendapat Hawkins (dikutip oleh Meida D. Wardhani, 2009) menyatakan bahwa konsumen yang tidak yakin pada dirinya sendiri dan mempunyai kepercayaan diri yang rendah maka akan membeli setiap produk yang mempunyai arti simbolik yang dianggap bisa menaikkan kepercayaan dirinya.

Pada hipotesis kedua dari analisis bivariate terdapat hubungan positif antara konformitas dengan perilaku konsumtif berbelanja online produk fashion pada mahasiswa pengguna aplikasi Instagram $\mathrm{Hal}$ ini berarti apabila semakin tinggi konformitas, maka semakin tinggi pula perilaku konsumtif berbelanja online produk fashion pada pengguna aplikasi Instagram. Penelitian ini memperkuat pendapat Santrock (dikutip oleh Petrus \& Arif, 2015) bahwa konformitas muncul ketika individu meniru sikap atau tingkah laku orang lain dikarenakan tekanan yang nyata maupun yang dibayangkan.

Pada hipotesis ketiga dari analisis multivariate koefisien $\mathrm{R}$ antara kepercayaan diri dan konformitas terhadap perilaku konsumtif sebesar 0,6I5. Dengan demikian hipotesis ketiga terdapat hubungan yang signifikan terhadap kepercayaan diri dan konformitas dengan perilaku konsumtif berbelanja online produk fashion pengguna aplikasi Instagram. Sehingga $\mathrm{R}^{2}$ sebesar 0,379 (37,9\%) menunjukkan bahwa penelitian ini dengan menggumeakan variabel kepercayaan diri dan konformitas memiliki hubungan yang signifikan terhadap perilaku konsumtif berbelanja online produk fashion pengguna aplikasi Instagra.

\section{PENUTUP}

\section{Kesimpulan}

Berdasarkan hasil penelitian dapat disimpulkan bahwa :

I. Terdapat hubungan negatif antara kepercayaan diri dengan perilaku konsumtif berbelanja online produk fashion pada pengguna aplikasi Instagram.

2. Terdapat hubungan positif antara konformitas dengan perilaku konsumtif berbelanja online produk fashion pengguna aplikasi Instagram.

3. Terdapat hubungan secara bersama-sama antara kepercayaan diri dan konformitas dengan perilaku konsumtif berbelanja online produk fashion pada pengguna aplikasi Instagram

\section{Saran}

Bagi yang ingin melakukan penelitian lebih lanjut tentang perilaku konsumtif diharapkan mempertimbangkan variabel-variabel lain yang dapat mempengaruhi perilaku konsumtif. Seperti dukungan sosial, harga diri, kontrol diri, lingkungan kerja dan variabel yang lainnya, agar 
berbelanja online produk fashion pada pengguna aplikasi Instagram menjadi sempurna.

Bagi konsumen terutama mahasiswa dengan kepercayaan diri yang tinggi diharapakan dapat mempertahankan keadaan yang sekarang dan juga dalam keadaan konformitas yang tinggi agar di turunkan dalam pertemanan yang memiliki dampak negatif agar perilaku konsumtif dalam berbelanja online produk fashion menjadi rendah

\section{DAFTAR PUSTAKA}

Ahmad Hidayat dan Candra Kurniawan. 2016. Pengaruh Konsep Diri dan Kepercayaan Diri terhadap Perilaku Konsumtif Pembelian Gadget pada Mahasiswa Fakultas Hukum Non Reguler Universitas Islam Riau. Jurnal An Nafs, IO (I)

Arie P. U. Kadi. 2016. Hubungan Kepercayaan Diri dan Self Regulated Learning terhadap Prokrastinasi Akademik pada Mahasiswa Psikologi 2013 Universitas Mulawarman. ejournal Psikologi, 4 (4)

Dias Kanserina. 20I5. Pengaruh Literasi Ekonomi dan Gaya Hidup terhadap Perilaku Konsumtif Mahasiswa Jurusan Pendidikan Ekonomi UNDIKSHA 2015. Jurnal Jurusan Pendidikan Ekonomi, 5. (I)

Eva Suminar dan Tatik Meiyuntari. 2015. Konsep Diri, Konformitas dan PerilakuKonsumtif pada Remaja. Jurnal Psikologi Indonesia, 4 (2)

Indah Haryani dan Jhon Herwanto. 2015.

Hubungan Konformitas dan Kontrol Diri dengan Perilaku Konsumtif terhadap Produk Kosmetik pada Mahasiswi. Jurnal Psikologi, I I (I)

Masayu N. Dwiputri. 2016. Hubungan Konformitas, Kepercayaan Diri, Locus Of Control, Strategi Coping dan Sensation Seeking terhadap Intensi Menggunakan Ganja di Kalangan Mahasiswa di Samarinda. ejournal Psikologi, 4 (3)

Selviana Syafitri. 2014. Pengaruh Harga Diri dan Kepercayaan Diri dengan Aktualisasi Diri dengan Komunitas Modern Dance di Samarinda. e-Journal Psikologi, 2 (2)

$\begin{array}{llll}\text { Made I. Yuliantari dan } & \\ & \text { Yohanes K. Herdiyanto. } 2015 .\end{array}$ Hubungan Konformitas dan Harga Diri dengan Perilaku Konsumtif pada
Remaja Putri di Kota Denpasar. eJournal Psikologi Udayana, 2

(I)

Sholikin, dkk. 20l4. Studi tentang Faktor Penyebab Perilaku Konsumtif Siswa Kelas X Administrasi Perkantoran di SMK Negeri I di Kota Gorontalo

Sri Wahyuni. 2014. Hubungan Antara

Kepercayaan Diri dengan Kecemasan

Berbicara di Depan Umum Pada Mahasiswa Psikologi. ejournal

Psikologi, 2 (I)

Nur Fitriyani, dkk. 2013. Hubungan Antara Konformitas dengan Perilaku Konsumtif pada Mahasiswa di Genuk Indah Semarang. Jurnal Psikologi Undip, 12 (I) 